\title{
HAPPY ONLIFE' - A VIDEO GAME TO SUPPORT MEDIATION ON INTERNET RISKS AND OPPORTUNITIES
}

\author{
Author: CHAUDRON, Stephane; DI GIOIA, Rosanna; GEMO, Monica \& LAGAE, Kaat \\ Institut for the Protection and Security of the Citizen (IPSC) - Joint Research Centre Comission - Italy
}

stephane.chaudron@jrc.ec.europa.eu; rosanna.di-gioia@ec.europa.eu; monica.gemo@jrc.ec.europa.eu; kaat.lagae@jrc.ec.europa.eu

\begin{abstract}
Children and young people are very active users of digital technology from an early age. Recent research shows that children learn quickly from mirroring the behaviour of parents, of older siblings and peers. On the one hand, children have acquired independency and skills within the digital world; on the other, they lack reflective and critical thinking as well as awareness about opportunities and risks such as cyber-bullying or digital identity theft. Active adult's mediation would allow for the integration of values and critical thinking but so far, adults seem poor active mediators and in need of practical tools of empowerment. Therefore, we developed Happy Onlife, a game to support players towards a happy online life. This interactive video game aims at empowering teachers and parents to actively guide children to become smarter, responsible, and respectful when using digital media. We chose an experimental and empirical approach and the design of the game repeatedly undertook the elicitation, representation and validation steps. Happy Onlife presents key messages about children's use,
\end{abstract}

overuse, and risks of misuse of digital technologies and provides simple and clear strategies of prevention, mediation or remediation. Tests beds have proved the efficiency of the video game's questions to prompt discussion between generations and to drives the players towards a responsible and safe digital media use. Happy Onlife can be considered as an effective tool to support adults' mediation to children for a healthy and safe internet and digital technology use.

\section{Key words}

Video game, digital living, serious games, educational gaming, digital mediation, cyber-security, digital safety, citizenship values, ethical aspects of new ICT technologies, learning.

\section{Introduction}

Education through video gaming is a concept that is increasingly looked at and evaluated in literature. This relatively new educational tool is mostly referred to as 'edutainment', 'educational gaming', 'elearning' or 'serious games' (Paraskeva, Mysirlaki \& Papagianni, 2010; Bellotti, Kapralos, Lee, MorenoGer \& Berta, 2013; Moreno-Ger, Burgos, MartínezOrtiz, Sierra \& Fernández-Manjón, 2008). Educational games are designed to have an impact on the target audience, which is beyond the pure entertainment aspect (Gee, 2007). Since children are exposed to digital devices at a younger and younger age and since they now intuitively learn how to navigate these devices, it is not surprising that educational institu- tions and industries are investing in implementing ICT (Information and Communication Technology) in learning activities. Educators nowadays also seem convinced to use ICT in a learning environment since research shows that the implementation of ICT clearly has an effect on the motivation of its users (Passey, Rogers, Machell \& McHugh, 2002; Hainey, Connolly, Stansfield \& Boyle, 2011). However, like Moreno-Ger et al. (2008) state, learning is the result of rich and varied activities and although it is obvious that ICT found their way into the classrooms, it is still not clear which kind of impact this has on learning outcomes (Scheuermann \& Pedró, 2009). That is one of the reasons why a cross-medium approach still 
seems to be preferable when it comes to learning achievements.

Next to this, when using ICT in class or not, educators as well as children need to be aware of the risks of this emerging digitalization and thus have a solid basic knowledge on the different devices, their possible use, misuse and possible consequences. As stated above, it is seen that in reality young children as well as adults often are insecure about their digital knowledge and that they would welcome further guidance and advice on this subject (Chaudron, et al., 2015). In this perspective and by taking the EU policy recommendations as bases for the work program, a toolkit was developed, i.e. a collection of easy and practical step-by-step awareness raising, mediation and remediation activities on risks and the digital world. The toolkit is named "Happy Onlife", based on the contraction of three words: happy-online-life. The aim of the toolkit is to empower children from 8-12, their parents and teachers in developing a happy, healthy online life. The Happy Onlife toolkit contains, amongst other tools, the Happy Onlife video game.

In this publication, the theoretical background and the development of this video game is discussed, within the context of the production of the entire complementary toolkit composed by a booklet gathering pragmatic activities, a board game and a carpet game. The step-by-step expansion of this toolkit is explained, as well as the results of its development and the dissemination of the toolkit. Next to this, further steps of research are discussed, like for example the upcoming evaluation of the toolkit by performing an impact assessment.

\section{Background}

The European Commission's Joint Research Centre's (JRC) mission is to provide EU policies with independent, evidence-based scientific and technical support throughout the whole policy cycle. Its work has a direct impact on the lives of citizens by contributing with its research outcomes to a healthy and safe environment, secure energy supplies, sustainable mobility and consumer health and safety. As part of the JRC, the Digital Citizen Security Unit strengthens trust and security of the European Citizen in a sustainable and inclusive ICT-based European society by performing scientific research on how emerging Information and Communication Technologies will impact on the security and privacy of citizens' daily life. The Digital Citizen Security Unit explores and investigates European and International agenda's to then import these criteria into their research goals to support directly European policy in an evidence-based way. In this framework, a project was set up in order to meet the existing need to educate children and adults on the opportunities and the risks of the digital world. Following the European Strategy for a Better Internet for Children (2012) and the EU Agenda for the Rights of the child (2011), children lack the right skills to deal with all emerging new media, as it will also be explained later on. To address this and other current gaps and problems related to children's use of ICT, a
European strategy was set up with a goal that is fourfold. First of all, Europe will stimulate the production of high-quality content online for children and young people. A second goal is for this online environment to be safe for children and the third is to fight against child sexual abuse and child sexual exploitation. A last intention of this European strategy, that may not be underestimated, is to step up awareness and empowerment. The strategy states that children, their parents, carers and teachers need to be aware of the risks children can encounter online as well as of the tools and strategies to protect themselves or cope with such risks. The project Happy Onlife thus is a perfect example of carrying out this strategy and substantiate it with a clear and goal-oriented product. The need for this projects is made explicit throughout the European agenda's and will be explained in brief in the next paragraphs.

It is given that the use of (new) media influences people's behaviour (Clay, 2003). In the digital era into which our society is evolving, it is essential that both children and adults understand how to associate with digital media and how they can use those media - in a healthy way - in their everyday life. Children and young people, nearly from birth, are very active users of digital tools nowadays; however this does not 
mean that they have acquired enough awareness about the risks and opportunities they can find in these new settings. Young people often lack those important skills and attitudes to use ICT tools in a safe way. On the other hand, adults (parents, educators, guardians) need to make an effort to bridge the generation and knowledge gaps (Jenkins, 2010). A recent qualitative study on children's behaviour with ICT and parental mediation shows that using ICT is mostly an individual activity amongst children. Parents have the tendency to 'keep an eye' on their children's activities but actually do not know exactly what their children or young teens do online and what kind of risks they are exposed to (Chaudron, et al., 2015). This study as well as the EU Kids Online studies (Livingstone, Haddon \& Görzig, 2012) recommend parents to share online activities with their kids and to talk to them about it, rather than leave them doing online actions that they might understand only partially or cannot talk about. As it happens with TV and movies, adults need to guide children and young people in reinforcing all positive messages that media are issuing and externalise concerns, which can become the subject of ethical and value-based discussions.

New digital competences are increasingly becoming an essential condition to take part in society and they are classified in different ways. The Institute for Prospective Technological Studies (IPTS) of the JRC recently published a Digital Competence Framework (Ferrari, Punie \& Brečko, 2013) that identifies five main areas regarding digital competences: Information, Communication, Content Creation, Safety and Problem Solving. These fields are then all divided into different digital skills that one can possess on three different proficiency levels (foundation, intermediate, advanced). Another description of digital skills is explained in the Proposal for a Recommendation of the European Parliament and of the Council on key competences for lifelong learning (2005). In this proposal, digital skills consist of: knowledge of media (classic and new ones) and skills and attitudes (as the ability to search, collect and process information and use it in a critical and systematic way, assessing relevance and distinguishing the real from the virtual and recognising the links). Individuals should build these skills to use tools to produce, to present and to understand complex information and to be able to use ICT to support critical thinking, creativity and innovation.

Children's online safety is an emerging theme in policy context and thus needs investigation in order to advise stakeholders in an evidence-based way. JRC researchers have been intensively investigating the digital citizenship and its related subjects. From this research emerged the need for empowering tools for children, teachers and parents providing more information, mediation and digital skills development.

To answer to this need for empowering materials, JRC is now developing the Happy Onlife toolkit, which is a set of tools and a review of practices to raise awareness about ethical usage of ICT that responds to current challenges raised by ICT, including online bullying and impacts on the offline child's life. It includes both digital and paper items (video game, booklet, board game, game carpet, tips etc.) to empower children's rights by preventing and mitigating ICT emerging issues through education, school and community co-vigilance. The toolkit's efficiency and impact will be assessed later in time, as now the first phases of game development are completed.

\section{Theoretical framework}

The Happy Onlife toolkit was conceived under a theoretical framework, which includes notions of Positive Psychology and Positive Technology together with Empowerment, Gamification, Meaningful Learning and Ecosystemic theories.

Positive Psychology and Positive Technology
Positive Psychology was an inspiration for the choice of the toolkit's name: Happy Onlife. In particular this approach drove the team to choose the term "Happy" instead of "Safe" or "Correct". Happiness is a fuzzy concept that can have different meanings to different individuals and in different contexts. According to the American psychologist and educator Martin Seligman, considered as the founder of Positive Psychol- 
ogy, the concept of happiness can be seen as a mental or emotional state in the wider construct of health, well-being and flourishing (Seligman, 2001). This definition is confirmed by the WHO (World Health Organization) statement published in 1946: "Health is a state of complete physical, mental and social wellbeing and not merely the absence of disease or infirmity" (WHO, 1946). As such, mental health is defined as a state of well-being in which every individual realises his or her own potential, can cope with the normal stresses of life, can work productively and fruitfully, and is able to make a contribution to his or her community, thus positive psychology explores human virtues, strengths and individuals' potential.

The Happy Onlife digital game has been designed combining goals and contents of Positive Psychology focusing on Seligman's PERMA theory (Seligman, 2002), which comprises five pillars to guarantee a state of health and happiness:

1. Positive emotions (internal and external pleasure);

2. Engagement, such as involvement, state of presence, or state of complete absorption in what one does as defined by the flow theory of Csikszentmihalyi (1990);

3. Positive Relationships (social ties and behaviours);

4. Meaning (meaningful experiences);

5. Accomplishment, i.e. realisation of tangible goals, sense of auto efficacy as conceived by Bandura (1997)

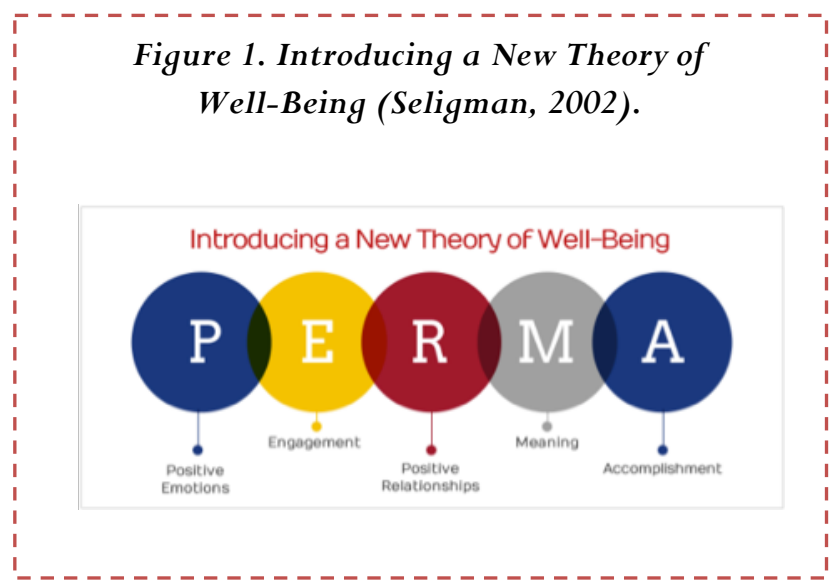

Positive Technology is an emerging scientific paradigm, whose final aim is to use technologies and ICT for improving the quality of our personal experience through affective and persuasive computing, serious gaming, simulation, e-health and virtual reality (Riva, et al., 2011).

Happy Onlife can be seen as an example of positive technology (Riva, et al., 2012) because of the improvement of personal experience, generation of strengths, awareness, critical thinking and resilience in human beings, organisations like schools and society in general.

\section{Empowerment}

Happy Onlife is a game for empowering children, adults, and the entire community - composed by both families and schools - in raising awareness of the risks and opportunities of internet and promoting the best online practices. The game supports parents and teachers in their active mediation in the use of digital technologies with children aged between 8 and 12 . Happy Onlife presents key messages about children's use, overuse, and misuse risks of digital media such as cyber-bullying, as well as simple and clear activities and strategies of prevention, mediation or remediation while reinforcing the sense of community.

"The sense of community is a feeling that members have of belonging, a feeling that members matter to one another and to the group, and a shared faith that members' needs will be met through their commitment to be together (McMillan \& Chavis, 1986)".

From a psychological point of view, the verb "to empower" defines the feeling of the individuals capacity of control over what happens. This feeling supports and encourages an individual to make the changes needed to deal with a given situation, even winning inner and outer resistance (Rappaport, 1984). Empowerment is both an individual and organizational process, applicable to systems with a structure and rules such as companies and schools. Individuals can strengthen their capacity for choice, selfdetermination and build and develop confidence. Empowerment through the development of personal skills and technical competences can mean for example, being able to analyse situations and communicate more effectively and respectfully with others. Within a community, empowerment implies co-operation, communication and trust between members. In addition to behaviours there are - as prerequisite - appro- 
priate structures, protocols and procedures in place, with effective sanctions against those who default or abuse the system. Punishing and sanctions cannot be the unique approach in an empowered community: having fun and celebrating achievements is also a must. In this way people have opportunities to meet and exchange views and opinions and at the same time learn and record what has been achieved and agreed.

Together with the game, the Happy Onlife toolkit proposes a series of activities to be arranged within the community environment: e.g. video-festival, theatre, role-playing, etc. These initiatives, as the game, are only a pretext to open debates and raise discussion on key messages about a balanced way of using digital media as well as use, overuse, and misuse risks of digital media such as cyber-bullying.

\section{Gamification}

Human beings have a psychological aptitude to game involvement. Play and games are incorporated in the human educational approaches from time immemorial. Gamification techniques can encourage people to perform those actions that are generally considered boring or not particularly interesting. It is usually considered as the addition of a (video) game in a context, as for example to an educational environment to create a new setting. A video game can definitely make an activity more fun, engaging and effective, but gamification means much more.

For example Detering, Dixon, Khaled and Nacke (2011) define gamification as "an informal umbrella term for the use of video game elements in nongaming systems to improve user experience and user engagement". According to Kapp (2012) gamification is "the use of game-based mechanics, aesthetics and game thinking to engage people, motivate action, promote learning, and solve problems ... while it is not the superficial addition of points, rewards, and badges to learning experiences". Furthermore, gamification embraces Fredrickson's (2004) broaden-and-build theory of positive emotions. According to this author, positive emotions are essential to the empowered development of individuals. Through positive emotions people can build new physical, intellectual, social and psychological resources, which can activate mechanisms and behaviours to better deal with critical and challenging situations. Positive emotions also produce flourishing pleasant moment, but over the long term as well as they represent means of achievement psychological growth and improved well-being over time (Fredrickson, 2001).

Happy Onlife game techniques fully adopt these definitions. On the one hand the game relies on playful elements for goals achievement (scoring system and end goal) and on the other hand it allows to experience pleasurable feelings as a sense of self-efficacy, self-assessment and self-realisation, agency and sense of community (Sailer, et al. 2013).

\section{Meaningful learning: "Learning by doing" - The experience full of meaning}

As human beings think, feel and act, the meaningful learning theory covers cognition, feelings and actions (Novak, 2002). The main purpose of this approach is to allow individuals to be active agents of their own personal learning process. The learning then becomes cognitive, emotional, experiential and, therefore meaningful.

Cognitive learning refers to the acquisition of knowledge and competences, which create the cognitive structure. The emotional aspects are represented by feelings experienced, including perceived self-efficacy and self-esteem which are certainly fundamental in the formation of the individual. The psychomotor learning allows the achievement of psychomotor skills and abilities: the ability to do. Knowledge thus integrates thoughts, feelings and actions and allows the individual to achieve a state of empowerment and involvement (Novak, 2002).

According to McGonigal (2011), the three phases mentioned above are part of the process of gameplay and contribute to the fulfillment of emotional needs, cognitive, physical hard work. These three phases are achieved by using games and serious games in the learning process as the player enacts cognitive functions, such as thinking, attention and memory as was also intended with Happy Onlife, by developing a proper game instead of an information package. The individual also experiences feelings that may be related either to the inner sphere or shared with playmates. 
The psychomotor learning will instead be linked to practice the ability of problem solving, multitasking and decision-making. The major benefit of meaningful learning consists of stronger cognitive and emotional memories.

\section{ZOPED (Zone Of Proximal Development) and peer or parental mediation}

Figure 2. Zone of Proximal Development (Vygotsky)

\section{Zone of Proximal Development}

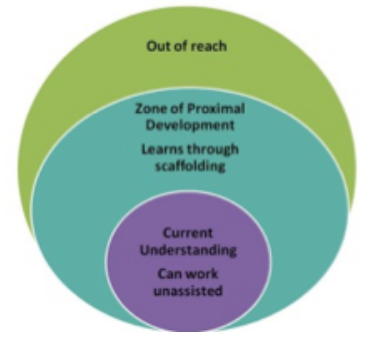

Happy Onlife embraces the social function of the game through Vygotsky's (1978) ZOPED (Zone Of Proximal Development) theory. By playing, children can experience the ability to change roles and learn to take different perspectives. The zone of proximal development is the distance between the ability to get a result from an individual without assistance and the result with the assistance of a partner that can explain, discuss, participate, suggest and address the child's attention. The mediator is generally represented by an adult, in particular either a parent or a teacher, but can also be an experienced peer in a certain task or an older child. This mediation allows activating those functions which are not yet activated individually.

The Happy Onlife game supports proximal development and opens a path to empower teachers and parents as mediators in guiding children to become smarter, responsible, and respectful when using media and helps them understand the ethical consequences behind the decisions they make online. Healthy digital children learn better and become healthy digital adults enabling them to reach their potential.

\section{Ecological Systems Theory}

The Ecological Systems Theory served as a base throughout the development of the Happy Onlife toolkit because the aim was to reach children as well as their educators and parents in order to try to obtain a more substantial learning effect.

Bronfenbrenner (1979) presented a conceptualisation of the child's environment (ecology) as a multilayered set of nested and interconnected environmental systems, all of whose 'agents' influence the development of the child but with varying degrees of directness (Mc Guckin \& Minton, 2014). Different systems are presented in which the child is in contact with different actors. These environmental systems are widely spread and applied throughout the academic world and are referred to as the micro-, meso, exo-, macro-, and chrono-systems.

Figure 3. Ecological Systems Theory (Bronfenbrenner, 1979)

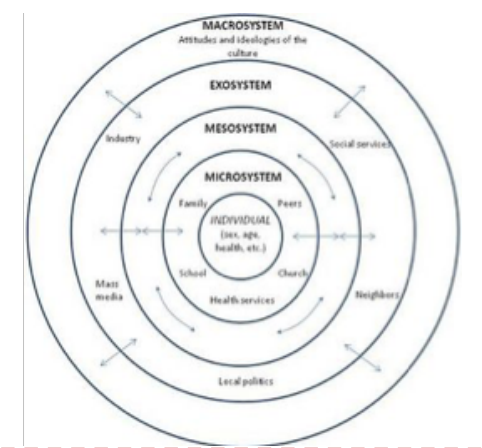

Figure 4. Ecological Systems Theory as applied to Happy Onlife

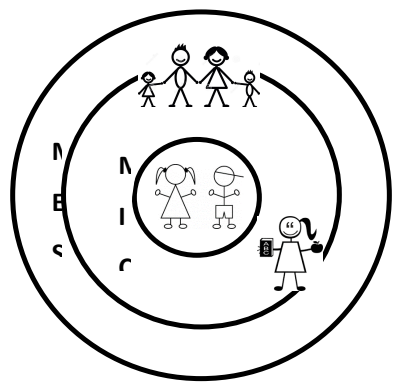

The model's application in educational context is variegated and different examples of the importance of the consideration of the ecosystem in education can be found. Gottfried, Gottfried and Bathurst (1988) 
investigated the child's ability to learn and concluded that this does not only depend on the quality of the instruction but also on the extent to which parents value scholastic achievement. Not only the microsystem but even the exo-system can exert an indirect influence on the child's learning.

This model served as the base to develop Happy Onlife for a triad of actors: children, parents and educators. The child himself is the main target of the game, which can be seen in the ecological model as the individual in the centre of figure 3 and 4. The microsystem is also addressed through the game, since learning of the child is influenced by parent's attitudes and mediation. The third main actor that was aimed at is the teacher and school in general, since school has of course a primary role in the child's edu- cation. By reaching out to parents as well as to schools on the micro-level, the game's impact on the child will hopefully increase. Apart from these three main actors, it is seen that of course other parts of the meso- and exosystem are also influencing individual learnings.

A specific example of the theory's application on Happy Onlife is the choice for a paper game. In this way, parents and children can play together at home and parents can actively mediate their children's behaviour with digital technology. Another example is the development of the carpet game, which has the purpose to encourage the teacher to play the game with the whole class.

\section{Methodology}

The actual Happy Onlife toolkit was developed using an experimental and empirical approach. In this section, the chronological development of the video game will be explained in detail. The present digital game was preceded by a paper version which was, on his turn, adapted from an online quiz. This crossmedia adaptation is a central and recurring theme in the development of the toolkit allowing the player/learner to repeat its experience in different contexts and media since learning is the result of rich and varied activities (Scheuermann \& Pedró, 2009).

\section{Paper game development}

A set of tools was developed based on the eSafety quiz from the Insafe project in 2010 (http://www.esafetykit.net/INSAFE). The prototype comprised a quiz reworked into a paper game inspired by the traditional "Snakes and Ladder game", combined with questions on the use, overuse and misuse of internet. These were grouped into four categories: ICT security, communication, cyberbullying and entertainment, which represent the main risks encountered and activities carried out by children online. Different icons were designed for every question category in order to guide the player/learner through the game.

The choice of a traditional paper game aimed at bridging the inter-generational gap, while enhancing the knowledge sharing and facilitating adult mediation. Adults entering into the game feel confident straight away, at the same level as the children. The rules of the first paper game were quite straightforward. When the player ends up on a square with an image, a question was asked to the player by its neighbour. If the question was answered correctly, the player could move one step ahead. If on the contrary the question was answered wrongly, the player was sent two steps back. The first player to reach the finish wins the game. This design approach is an iterative process that maximises the participation of various actors. Among these actors are all potential users: children, educators, parents, peers. To formalise the toolkit's requirements and its design, the project team repeatedly undertook elicitation, representation and validation steps.

A target group of children aged 8 to 12 years old was determined in order to develop the content to the level of their knowledge. The children in this age group in particular are seen as independent users of digital technology and are already present on Social Networks despite their young age. It is this group of children that needs to be armed against the risks of ICT since challenges can become even larger when entering high school. On the other hand, giving them insight in the opportunities of ICT can empower 
them to explore ICT in a positive and advantageous way.

During school year 2012-2013, several primary $(n=105)$ and secondary $(n=76)$ students of the European School of Varese (Italy) were entrusted with the task to test the game, the content of its questions, its phrasing and pertinence. Next to this, the format of the game was evaluated, for example its accessibility by age and its pace. By raising awareness amongst the children, another goal was to make the children themselves mediators to their parents.

From the evaluation of this first testing phase, it was clear that the board game was efficient in questioning behaviour with digital technologies like internet use, video gaming, TV on demand etc. Lively discussions emerged amongst children and adults on different subjects while using the game as a starting point. This clearly showed that the game's first objective, bridging the generational and knowledge gap, was met. Also, the "Snakes and Ladder game" inspiration worked very well as no time was lost in trying to understand the rules of the game and it allowed the player to enter into the game immediately. On the other hand, the feedback showed that more questions were desirable and that some questions needed to be reworked as they were outdated. All the questions regarding e-mails, spam, and viruses were somehow not up-to-date to the students while on the other hand questions about Social Networks and smartphones were under-represented. The phrasing of the questions was not always adapted to the level of the children and thus needed some adaptation as well. Furthermore, during the tests it became clear that the concept of the game needed to be enlarged to an entire toolkit that consists of varied pragmatic and easily-implemented awareness-raising activities to be proposed in school and at home.

Based on the results of the infield tests, the board game questions were reworked, others were created emphasising the use of Social Networks and smartphones and questions categories were customized to Watch Out! (Security), Let's Chat (Communication), Stop Online Bullying (Cyber-bullying) and Play Safely (Entertainment). The deliberate choice was made to not let players lose a turn when answering wrongly to a question but to direct them to a 'stop square' next to the question square in order to think over their reply. In this way the players do not lose a turn but they do lose some progression to the finish. In 2014 new tests in Italian schools (Angera, Ispra, Laveno) were arranged to fine-tune and validate the game concept.

As children and young people are very active users of digital technology from an early age, a digital version of the game became necessary to engage them to play multiple times in a way that is attractive to them and coherent with the theme. It will become clear from the next section that the development of this video game was a long-term project in which again different test phases were implemented to meliorate its functionalities and purposefulness.

A complementary version to the paper game is the Happy Onlife carpet, released to make children represent the avatars themselves. This embodied approach is a good addition to the paper version since it makes it possible to interact with more people, for example a class group around only one game. It is clearly demonstrated by developmental psychologists that action has an extraordinary influence on learning (Held \& Hein, 1963; Piaget \& Cook, 1952). Kontra, Goldin-Meadow \& Beilock (2012) state that not only does movement has a powerful effect on learning at the beginning of life, it continues to impact the way we experience the world throughout development and into adulthood.

\section{Digital game development}

When the decision was made to turn the board game into a video game, the research team was first and foremost expanded with a professional game developer. His task was to make the existing board game into a digital game to later transform it into a smartphone application.

As the board game was already graphically designed, the choice was made to maintain a coherent visual identity for both products. Therefore, the visual identity of the board game and its digital version has been developed in parallel since October 2014. For the video game however, a specific visual concept was added because of its different setting. The game board is floating in a space atmosphere and the tokens are turned into spaceships. This choice was also based on 
the first tests with young users, as is explained later on.

The target group of the digital game is again children from 8 to 12 years old. Since the research centre is based in Italy, local resources were used for the field tests, meaning local schools. Therefore, the first digital version of the game was developed in Italian, quickly followed by an English version. Later on, two additional languages (French and Dutch) were added in order to present the game at the European Commission's Open Day in Brussels in May 2015, where the audience was rather French or Dutch speaking. The questions of the game are translated precisely hence are the same for every language.

Since the video game still presents the actual game board of the paper game, an objective was to make the children visually experience the video game as they would do with the board game. To this end three views have been developed with an increasing level of improved visual effect that provide more and more gaming motivation, engagement and appeal: a 2D environment showing a layout with a look and feel similar to the paper version that gives the full overview of the entire map; a 3D environment with a rotating 2D map and 3D avatars (spaceships) being displaced onto it with 3D navigation; a 3D+ environment with 3D avatars (spaceships), 3D map and 3D navigation that provides a close-up view of the gaming plot (see figures 5, 6, 7).

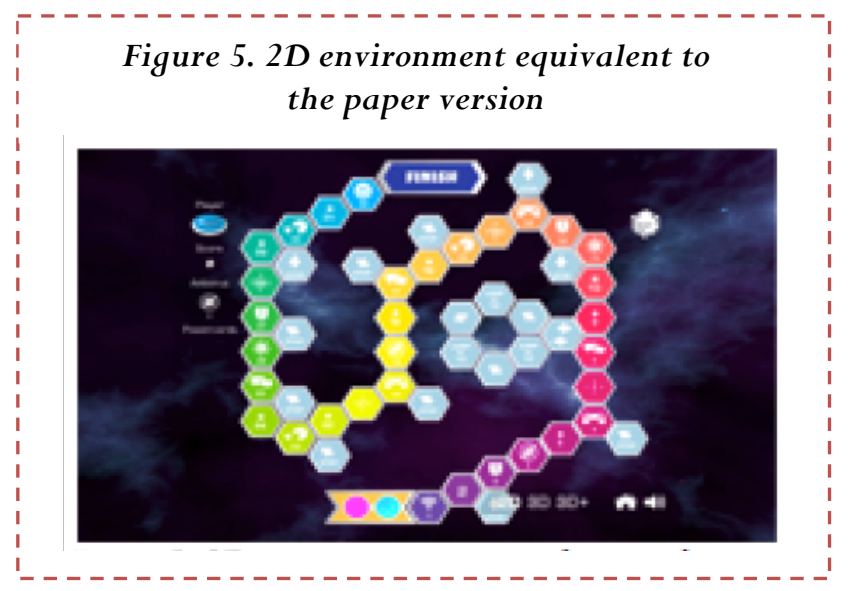

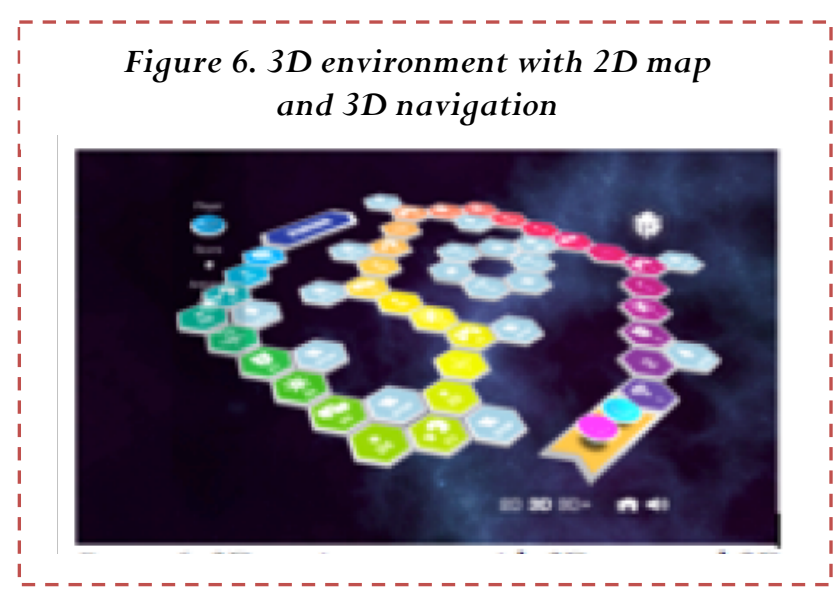

Figure 7. 3D + Environment with $3 D$ map and 3D navigation

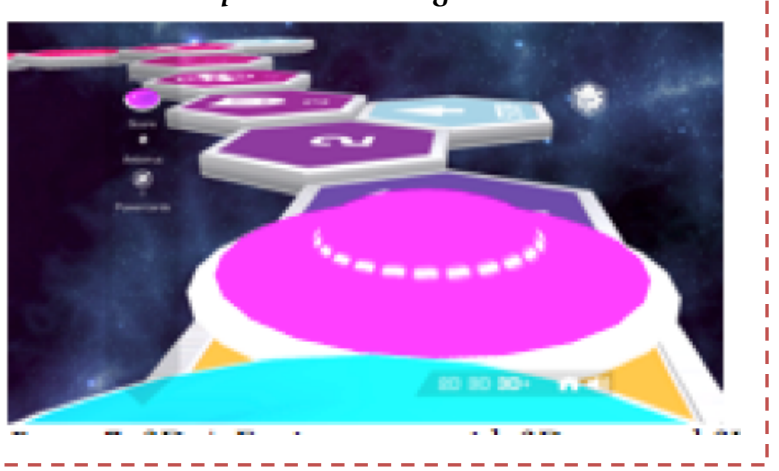

The Happy Onlife digital version has been developed based on Unity 3d 4.6 cross-platform game engine that allows the deployment of the game on multiple mobile platforms (Apple Store, Android, Windows Phone) and on the Web.

A first version of the video game was tested in January 2015 followed by a second test phase with an adapted version in April-May 2015. Both adults and children were included into the two test phases.

The first field test was carried out with random users $(n=8)$ that were asked to play the game on the computer and tell the researcher everything they see and experience while playing the game. Afterwards, they were asked what they would like to see differently in a next version. The children $(n=3)$ as well as the adults $(n=5)$ gave their distinct feedback and from this test, it became immediately clear that the online version could not be a simple transfer from the board game to the web. According to the first test group, the initial version of the online game was not dynamic enough. The initial version of the digital game was too slow, lacking rhythm and interactions. A return- 
ing comment was the fact that there were too many empty squares on the board, on which the player did not have any task assigned. Next to this, the beginning of the game was not self-explanatory. The test group did not know how to start the game and it was difficult to understand which player was leading the turn.

In reaction to the first test phase, some adaptations to the online game were made. The most important change, which is also the one that now differentiates the board game and the online game, was the implementation of new 'event squares' with the purpose to make the game more dynamic. The 'lucky cards' were added to fill the empty squares. A lucky card gets you either to randomly lose or win points according to actions related to the digital world (see figure 8). In addition to 'lucky cards', 'move cards' were inserted, telling you to move forward or backward on a randomized choice of steps (see figure 9). To make the beginning of the game self-explanatory, different options were considered. A video tutorial at the start was one of the options, but this would have probably implied making children lose interest. Next to this, it would have meant the children could not immediately start the game. In the end a visual strategy was chosen to make the beginning of the game more distinct. The dice was made bigger and a flashing border was added around the dice whenever it is the player's turn to click on it. A little pop-up screen tells which players turn it is (see figure 10).

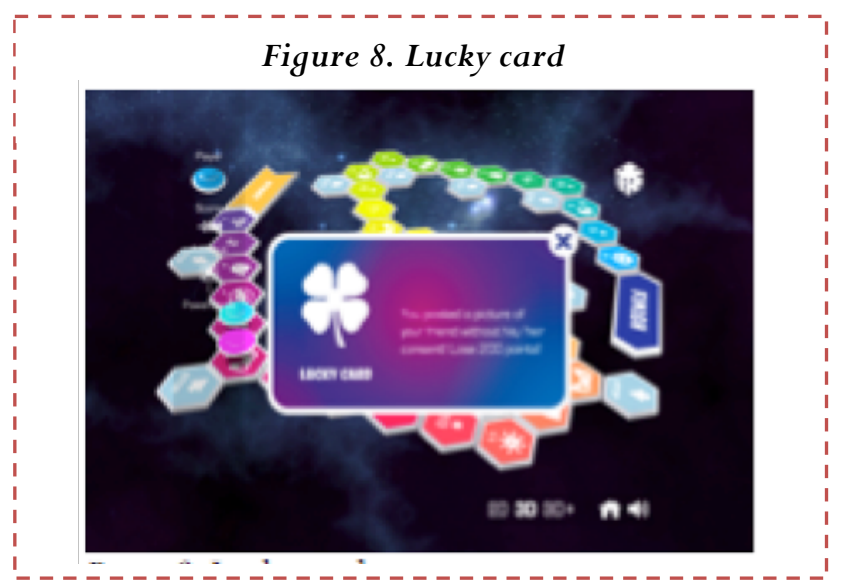

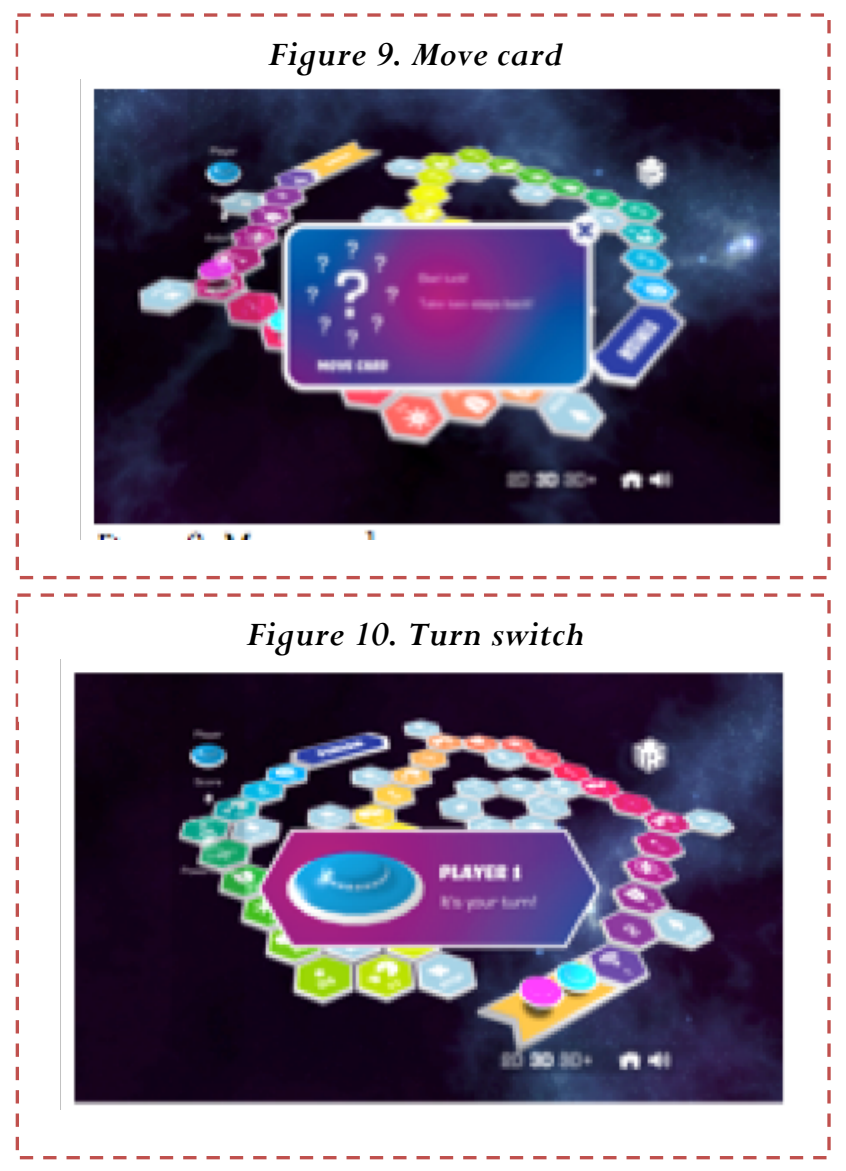

In line with addressing the higher pace of the video game compared to the paper game, the decision was made to include a scoring system into the digital version. In this way, children are highly motivated to gain as much points as possible and thus reflect deeper on the questions. The choice for a scoring system implied that only one of the answer possibilities could be the correct answer in order to gain points when choosing the right alternative. However, for the board game, questions were produced to evoke discussion and for that reason more than one answer could be the correct one, as explained on the cards themselves. Hence, the existing questions were reworked with the intention to have four answering possibilities for every question with only one being the correct alternative. If the correct answer is chosen in a first attempt, 1000 points are gained. If the player does not answer correctly in first attempt, a second chance is given for which the player can still gain 500 points if the answer is correct. Similar to the board game, when answering wrongly, the player is directed to a 'stop square' next to the 'question square' to think over his reply. 
The second test phase with the new version of the video game gave a clear idea of the games' strengths and weaknesses. Again, the test group consisted of both adults $(n=30)$ and children $(n=120)$. The major part of the test group was consulted randomly at the European Commission's Open Day in Brussels while some additional testers were recruited in the researchers' work environment. Most of the comments from the adult population were related to technical adjustments and fixing bugs. When testing the game with the children (8-12 years old) and their parents in a multilingual environment (IT, EN, FR, NL), the major impression was that some of the answers to the questions were ambiguous. Because the parents and the children mostly played together, a good synergy with educational discussions was seen and thus some of the answers actually did not seem to be wrong when discussing them more in depth. From this, a new revision of the questions was conducted based on the feedback received from the families.

An ongoing and endless process in this case is to keep the content of the game questions up-to-date. Since the digital world is changing very quickly, the questions need updates whenever they do not fit the actual situation anymore (e.g. the functionality update of Facebook tagging caused to review the correct answer). Given the difficulty to fulfil this task, a disclaimer was added to warn about the validity of the content and strategies at publication time that could eventually become obsolete in time. In this respect the digital version is easier to be updated and improved than its printed version.

After developing an icon for the game to represent it in the different online stores, at this very moment, the app version of the game is being technically tested. Some issues already turn up, like the questions not being readable on some smartphone screens, which now puts the team up to facing new challenges in order to make the app version successful as well. With the long term aim children playing together on different devices, the first step now is to make the app version running in the best possible way.

\section{Results}

Even though the development of the toolkit is an ongoing process, we can now already report on preliminary results of the development. The Happy Onlife paper version is currently available in English and in Italian. The digital game is playable online in English, Italian ${ }^{1}$ and a beta-version is ready in French and in Dutch but not available to the broad public yet. Versions in other languages will be available at a later stage.

After the official presentation in February 2015 at the event 'Safer Internet Day Italy', organised in Milan, many schools and institutions have requested a copy of the toolkit. More or less 50 copies of the toolkit are now already handed out to the public. The game raised much interest by major Italian educational,

\footnotetext{
${ }^{1}$ The Happy Onlife paper toolkit can be ordered through email or freely downloaded from the JRC Science Hub (https: / / ec.europa.eu/jrc/en/scientific-tool/happyonlife-game-raise-awareness-internet-risks-andopportunities). The web version of the game is accessible online at this link: http://web.jrc.ec.europa.eu/happyonlife/.
}

societal and governmental representatives (MIUR Ministero dell'Istruzione, Università e Ricerca, Regione Lombardia, CAM - Centro Ausiliario per i problemi minorili, Rotary Club, Senato Italiano for the bill on cyber-bullying).

Results from the initial dissemination to schools are encouraging. The Happy Onlife game opens a path to empower teachers and parents in actively guiding our children to become smarter, responsible and respectful when using media and it helps them to understand the ethical consequences behind the decisions they make online. An example of the informal learning strategies that can be delivered through the Happy Onlife game is presented on a video lesson recorded by a secondary Italian class in Sesto Calende (Happy Onlife uso consapevole di internet https: / www.youtube.com/watch?v=kHr3EiWgbk $\underline{\mathrm{M}}$ and https://gudidattica.wordpress.com/).

The discussions in class show that on the one hand, children have acquired skills in interacting with the digital world; but on the other, sometimes they lack reflective and critical thinking as well as awareness 
about risks and opportunities. To fill this gap the teacher engaged all the class in active mediation. The quiz questions of Happy Onlife on the use of internet, social networks, and online games prompted discussion and allowed the moderator to drive the players towards a responsible and balanced way of using digital media. This video shows that Happy Onlife is effective in supporting active adult medi- ation and that it can allow for the integration of values, critical thinking and raising awareness about possible risks, challenges and opportunities.

By the end of this year Happy Onlife should also be released on the different mobile platforms (Apple Store, Android and Windows Phone) to allow major diffusion and playability.

\section{Discussion}

The primary aim of the Happy Onlife toolkit is to raise awareness amongst children and adults on the risks and opportunities of the digital life. In the discussion, this aim is evaluated in the light of the toolkit's theoretical framework on the one hand and its preliminary results on the other hand.

Digital competences are today becoming a part of our daily life and for children and adults to become more competent, educational tools are needed. By looking at the recently developed Digital Competence Framework as described above (Ferrari, Punie \& Brečko, 2013), it is seen that the different themes of the Happy Onlife game correspond to three out of five areas identified in this framework. Most of the questions in the present game fall into the categories Information, Communication and Safety since the aim of the game is to increase awareness and safety skills. Furthermore, as the target group of the game is children from 8-12, questions on the areas Content Creation and Problem Solving are less present, as these themes seem to include more advanced digital competences than the ones mastered in general by children from 8-12 today. Nonetheless, they could be integrated in a future version of the game.

Different theoretical approaches influenced the development of the Happy Onlife toolkit. This solid theoretical background is necessary to cater for the definition of an educational game as stated by Gee (2007): "Educational games are designed to have an impact on the target audience, which is beyond the pure entertainment aspect". In order to increase the learning effect of a game, it is important to start its development by outlining the specific learning goals the game needs to affect and in that light construct a substantial theoretical framework. The Happy Onlife toolkit was conceived following notions of Positive Psychology,
Empowerment, Gamification, Meaningful learning as well as the Zone of Proximal Development Theory and the Ecological Systems Theory. The combination of these different but complementary approaches led to an educational toolkit that can now hopefully reach the set goals in a systematic and evidence-based way.

The transformation of a board game into a digital game was, and still is, an interesting exercise. In the first steps of the game development, it was obvious that the video game could not be a simple transfer from the board game into the online sphere. The most important adaptations concerned the pace of the game and hence finding a way to speed up the video game as it needed to be more dynamic than the board game. By implementing 'lucky cards' and 'move cards', the game became less static and at the same time the educational value was increased due to the information on the 'lucky cards'. It was interesting to observe how children as well as parents were curious to discover on which square they would end because this confirmed that the visual coding for the squares (an icon for every type of square) was understandable and successful.

Next to this, experiments with the different views of the board of the game gave insight in different preferences of different age groups. The $3 \mathrm{D}+$ view increased the interest of the young users of age 8 to 12 . Older users prefer the 3D environment which gives a global view of the board game but is still dynamic. Very few users opt for the 2D visualisation when playing. However, the choice was made to keep the 3 different views in the game since this was also a way to let children explore functionalities and in this way make the game more interactive. Even though little players chose the $2 \mathrm{D}$ view, it still resembles the ori- 
ginal board game best and that is why it was considered as important to keep this visualisation. When in the future a multiplayer game is developed, this view might gain popularity as it will be easier to see the positions of different players.

The results show that the meticulous development of the game has paid off. The feedback of the first dissemination is already positive since schools and Italian educational, societal and governmental representatives indicate the great educational value of the toolkit. However, this does not mean the product is finished. Still a lot of future development and adaptation needs to be done. Hopefully, users will share their feedback in order for the team to insert adaptations to meet the needs of the users.

Even though the content of the game will need to be updated along with the fast-developing digital world, content adaptations were already made based on the feedback of different test groups. The intention was to develop questions that explore contents as close as possible to the children's environment and at the same time not exposing them to content that they do not know yet. The different test phases showed that the content of the game is now in line with what children of the aimed age group understand. As intended, the questions evoke discussion with peers, parents or teachers and empower the children to actively think about the chosen subjects.

For future purposes, what is most important at this time is to continue translating the original game in different European languages to make the dissemina- tion range as broad as possible and to answer to the lack of valuable non-EU based language resources. As stated above, the app version of the digital game needs to be examined thoroughly in order to, in a next phase, make it possible to develop a multiplayer game.

Furthermore, an impact assessment needs to be performed to make sure the correct outcomes are reached. This assessment is foreseen to be carried out in the autumn of 2015. For the game to be considered as a viable educational tool, some means of testing and progress tracking must be provided. In terms of assessment, a formative approach would be best, whereby the testing is implemented and presented throughout the entire learning process and continuously monitors progress and failures (Bellotti, Kapralos, Lee, Moreno-Ger \& Berta, 2013). Developing an in-game assessment would be something to consider, since research shows it provides a detailed and reliable assessment and it would overcome limitations in the standardized approach (Bellotti, Kapralos, Lee, Moreno-Ger \& Berta, 2013). This would however mean that the game design needs to be adapted in order to collect educational data during the game itself. If impact needs to be assessed, the game would need to measure preconceptions and understandings of the online life in order to evaluate how these understandings improve by playing the game. A more realistic scenario at this phase in the game development would be to develop a childfriendly questionnaire to test understandings of the online world longitudinally.

\section{Conclusions}

As children and adults themselves stated to be insecure about their digital knowledge and in that respect wanted further guidance and advice on this subject (Chaudron, et al., 2015) and because of the increased policy attention to children's digital safety, the Happy Onlife toolkit was developed by the Joint Research Centre (JRC) of the European Commission. Its primary purpose is to raise awareness about ethical usage of ICT that responds to current challenges raised by ICT, including online bullying and impacts on the offline child's life. The toolkit is aimed at children from 8-12 years old, their parents and their teachers and it includes both digital and paper items (video game, booklet, board game, game carpet, tips, etc.) to empower children's rights by preventing and mitigating ICT emerging issues through education, school and community co-vigilance.

The game development is based on different theories and in this way tries to increase its impact as much as possible. This article demonstrated that developing a video game is not equal to transferring an existing board game to the web. Throughout different evaluation phases, it was seen that more action needed to be implemented to address the high pace of the video game compared to the paper game and that a more 
straightforward way of scoring needed to be developed, since there was no possibility of having different correct answers if a point rewarding system was implemented.

As a result of a meticulous development, the Happy Onlife toolkit in English and Italian is now available on request including the digital game available on the web. The first dissemination results to Italian schools are promising. Happy Onlife is efficient in supporting active mediation and value-based discussion and the transfer of knowledge while bridging the generational gap is accomplished. The Happy Onlife game seems as well to empower children, teachers and parents in becoming smarter, responsible and respectful when using media and the toolkit helps in understanding the ethical consequences behind the decisions they make online. However, less is still known about the game's effects and skills development on the long term. A structured impact assessment needs to be done in order to identify its specific learning outcomes.

Future development steps include the expansion of the current version to a multiplayer version and the launch of a smartphone application for playing the digital game.

\section{References}

- Bandura, A. (1997). Self-efficacy: The exercise of control. New York, NY: W. H. Freeman.

- Bellotti, F., Kapralos, B., Lee, K., Moreno-Ger, P. \& Berta, R. (2013). Assessment in and of Serious Games: An Overview. Advances in HumanComputer Interaction, vol. 2013. doi: $10.1155 / 2013 / 136864$

- Bronfenbrenner, U. (1979). The Ecology of Human Development: Experiments by Nature and Design. Cambridge, MA: Harvard University Press.

- Chaudron, S. et al. (2015). Young children (0-8) and digital technology: A qualitative exploratory study across seven countries (528pp). JRC 93239. Joint Research Centre, European Commission.

- Clay, R. (2003). Unravelling new media's effects on children. Monitor on Psychology, 34 (2), 40. Retrieved

from http: / / www.apa.org/monitor/feb03/unraveling. $\underline{\mathrm{html}}$

- Csikszentmihalyi, M. (1990). Flow: The psychology of optimal experience. New York, NY: Harper \& Row.

- Detering S., Dixon D., Khaled R. \& Nacke L. (2011, september). From game design elements to gamefulness: defining gamification. Paper presented at MindTrek, Tampere, Finland. Abstract retrieved

from https://www.cs.auckland.ac.nz/courses/compsci 747s2c/lectures/paul/definition-deterding.pdf
- EC (2005). Proposal for a Recommendation of the European Parliament and of the Council on key competences for lifelong learning, COM (2005) 0548 final.

- EC (2011). Communication from the commission to the European Parliament, the council, the European Economic and Social Committee and the Committee of the Regions: An EU Agenda for the Rights of the Child, COM (2011) 0060 final.

- EC (2012). Communication from the Commission to the European Parliament, the Council, the European Economic and Social Committee, and the Committee of the Regions: European Strategy for a Better Internet for Children, COM (2012) 196 final.

- Ferrari, A., Punie, Y., Brečko N. (2013). DIGComp: A Framework for Developing and Understanding Digital Competence in Europe. JRC83167. Joint Research Centre, European Commission.

- Fredrickson, B. L. (2004). The broaden-and-build theory of positive emotions. Philosophical Transactions of the Royal Society of London Society B: Biological Sciences; 359, 1367-1378. doi: $10.1098 /$ rstb. 2004.1512

- Gee, J.P. (2007). What Video Games Have to Teach Us About Learning and Literacy ( $2^{\text {nd }}$ ed.). New York, NY: Macmillan.

- Gee, J. P. (2007). Good video games and good learning: collected essays on video games, learning, and literacy. New York: Peter Lang. 
- Gottfried, A.E., gottfried, A.W. \& Bathurst (1988). Maternal employment, family environment, and children's development: Infancy through the school years. In A. E. Gottfreid \& A.W. Gottfried (Eds.), Maternal employment and children's development: Longitudinal research (pp. 11 58). New York, NY: Plenum Press.

- Hainey, T., Connolly, T., Stansfield, M. \& Boyle, E. (2011). The difference in motivations of online gameplayers and offline game players: a combined analysis of three studies at higher education level, Elsevier Computer \& Education, 57 (4), 2197-2211. doi: 10.1016/j. compedu.2011.06.001

- Held, R. \& Hein, A. (1963). Movement-produced stimulation in the development of visually guided behavior. Journal of Comparative and Physiological Psychology 56(5), 872-876. http://dx.doi.org/ $10.1037 / \mathrm{h} 0040546$

- Kapp, K. M. (2012). The gamification of learning and instructions: game-based methods and strategies for training and education. San Francisco, CA: Pfeiffer.

- Kontra, C. E., Goldin-Meadow, S., \& Beilock, S. L. (2012). Embodied Learning Across the Life Span.

- Topics in Cognitive Science, 4,731-739. doi: 10.1111/ j.175 6-8765.2012.01221.x

- $\quad$ Livingstone, S., Haddon, L., \& Görzig, A. (2012). Children, risk and safety on the internet: Kids online in comparative perspective. Bristol: The Policy Press.

- McGonigal, J. (2011). Reality is broken. New York: Penguin Books.

- Mc Guckin, C. \& Minton, J. (2014). From Theory to Practice: Two Ecosystemic Approaches and Their Applications to Understanding School Bullying. Australian Journal of Guidance and Counselling, 24 (01), 36-48. doi: http://dx.doi.org/10.1017/jgc.2013.10

- McMillan, D.W. \& Chavis, D.M. (1986). Sense of community: A definition and theory. Journal of Community Psychology, 14(1), 6-23. doi: 10.1002/1520-6629(198601)14:1<6::AID JCOP2290140103>3.0. CO;2

- Moreno-Ger, P., Burgos, D., Martínez-Ortiz, I., Sierra, J. L. \& Fernández-Manjón, B. (2008). Edu- cational game design for online education. Computers in Human Behavior, 24 (6), 2530-2540

- Novak, J.D. (2002), Meaningful learning: the essential factor for conceptual change in limited or inappropriate propositional hierarchies leading to empowerment of learners. Science Education 86 (4), 548-571. doi: $10.1002 /$ sce. 10032

- Paraskeva, F., Mysirlaki, S. \& Papagianni, A. (2010). Multiplayer online games as educational tools: facing new challenges in learning. Computers and Education, 54 (2), 498-505. doi: 10.1016/j.compedu.2009.09.001

- Passey, D., Rogers, C. G., Machell, J., \& McHugh, G. (2002). The Motivational Effect of ICT on Pupils: A Department for Education and Skills Research Project 4RP/2002/050-3.

- $\quad$ Piaget, J. \& Cook, M. T. (1952). The origins of intelligence in children. New York, NY: International University Press.

- Prensky, M. (2001). Digital Game-based learning. New York, NY: McGraw-Hill Inc.

- Prensky M., Gee J.P. (2006). Don't bother me mom - I'm learning! Minnesota: Paragon House Publishers.

- Rappaport, J. (1984). Studies in empowerment: Introduction to the issue. Prevention in Human Services, 3, 1-7. doi: 10.1300/J293v03n02_02

- $\quad$ Riva, G., Villani, D. \& Grassi, A. (2011). Tecnologie emotive. Nuovi media per migliorare la qualità della vita e ridurre lo stress. Milano: LED Edizioni Universitarie.

- Riva, G., Baños, R.M., Botella, C., Wiederhold, B.K. \& Gaggioli, A. (2012). Positive Technology: Using Interactive Technologies to Promote Positive Functioning. Cyber psychology, behaviour and social networking, 15 (2), 69-77. doi: 10.1089/cyber.2011.0139

- Sailer, M., Hense, J., Mandl, H. \& Klevers, M. (2013). Psychological Perspectives on motivation through Gamification. Interaction Design and Architecture(s) Journal, 19, 28-37.

- Scheuermann, F. \& Pedró, F. (2009). Assessing the Effects of ICT in Education: Indicators, Criteria and 
Benchmarks for International Comparisons. (211pp.). Joint Research Centre, European Commission.

- Seligman, M.E.P., Csikszentmihalyi, M. (2000). Positive psychology. American Psychologist, 55, 514.

- Seligman, M.E.P. (2001). Flourish: A visionary new understanding of happiness and well-being. New York: Free Press.

- Seligman, M.E.P. (2002). Authentic happiness: Using the new positive psychology to realize your potential for lasting fulfilment. New York: Free Press.

- Vygotsky, L.S. (1978). Mind in Society: The Development of Higher Psychological Processes. Cambridge, MA: Harvard University Press.

- WHO (1946). Preamble to the Constitution of the World Health Organization. WHO, New York, USA.

\section{Forma de Citación}

CHAUDRON, Stephane; DI GIOIA, Rosanna; GEMO, Monica \& LAGAE, Kaat: Happy onlife' - A video game to support mediation on internet risks and opportunities. Revista Communication Papers, $\mathrm{N}^{\circ} 6$, páginas 47 a 62. Departamento de Filología y Comunicación de la Universidad de Girona. Recuperado el de de 2 de: http://www.communicationpapers.es 